\title{
Oral Ulceration an Overlooked Complication of Mycophenolate Mofetil in a Renal Transplant Recipient
}

\author{
Department of Surgery, Seoul National University College of Medicine', \\ Transplantation Research Institute, Seoul National University Medical Research Center ${ }^{2}$, Seoul, Korea \\ Sang Hyun Ahn, M.D. ${ }^{1}$, Seung-Kee Min, M.D. ${ }^{1}$, Sang II Min, M.D. ', \\ Seong Yup Kim, M.D. ${ }^{1}$, Sang Joon Kim, M.D. ${ }^{1,2}$ and Jongwon Ha, M.D. ${ }^{1,2}$
}

Mycophenolate mofetil (MMF) is being widely used as a maintenance imunosuppressive therapy in renal transplant patients. Myelotoxicity and gastrointestinal symptoms are the well-known adverse effects of this immunosuppressant. However, there areexistonly two reports on oral ulceration associtated with MMF. Although oral ulcerations are not life-threatening, they may seriously affect the quality of life. We report ourthe experience of a case of a 57-year-old female patient with painful oral mucosal ulcerations that improved following MMF discontinuation.

Key Words: Mycophenolate mofetil, Oral ulcer, Kidney transplantation 중심 단어: Mycophenolate mofetil, 구강 궤양, 신장이식

\section{Introduction}

A triple-drug therapy regimen including mycophenolate mofetil (MMF) significantly reduced the rate of acute rejection and treated refractory rejection episodes successfully compared to therapy with steroid and cyclosporine(1). Such triple-drug regimen including MMF is widely accepted in the field of transplantation.

MMF is rapidly hydrolyzed into mycophenolic acid (MPA) after oral administration and is absorbed in the gastrointestinal tract(2). MPA selectively inhibits purine synthesis, preventing $\mathrm{T}$ and $\mathrm{B}$ cell proliferations. However, MMF is well tolerated generally even though it has some side effects. The most commonly reported adverse effects are gastrointestinal symptoms, such as diarrhea, indigestion, nausea, vomiting, abdominal pain and gastroesophageal reflux(3). Bone marrow suppression is another well known side effect. Most

Correspondence: Jongwon Ha, Department of Surgery, Seoul National University College of Medicine, 101 Daehak-ro, Jongno-gu, Seoul 110-744, Korea Tel: +82-2-2072-2991, Fax: +82-2-766-3975 E-mail: jwhamd@snu.ac.kr

Received : March 21, 2011, Revised : April 27, 2011 Accepted : May 27, 2011 adverse events are self-limiting and resolve with dosereduction. In addition, two cases of MMF toxicity manifested as severe oral ulceration have been reported in the literature $(4,5)$.

We herein report a case of 57-year-old female patient who developed severe oral ulcerations during MMF therapy and improved after cessation.

\section{Case Report}

A 57-year-old female patientwas maintained on hemodialysis for 3 years due to diabetes-related end stage renal disease (ESRD). She received a living-donor kidney transplantation from her 54-year-old sister. The blood types of donor and recipient were $\mathrm{Rh}+\mathrm{A}$ and $\mathrm{Rh}+\mathrm{AB}$, respectively. Human leukocyte antigen (HLA) crossmatch was negative and HLA A, B and DR loci were mismatched in two among six. Panel reactive antibody (PRA) to class I and II were 34\% and 20\% respectively. White blood cell (WBC) counts were $8,060 / \mathrm{mm}^{3}$, hemoglobin $10 \mathrm{~g} / \mathrm{dl}$ before operation. Her maintenance immunosuppressive regimen around two weeks of postoperative days was comprised of tacrolimus (initial dose of $0.07 \mathrm{mg} / \mathrm{kg}$, twice a day, target 

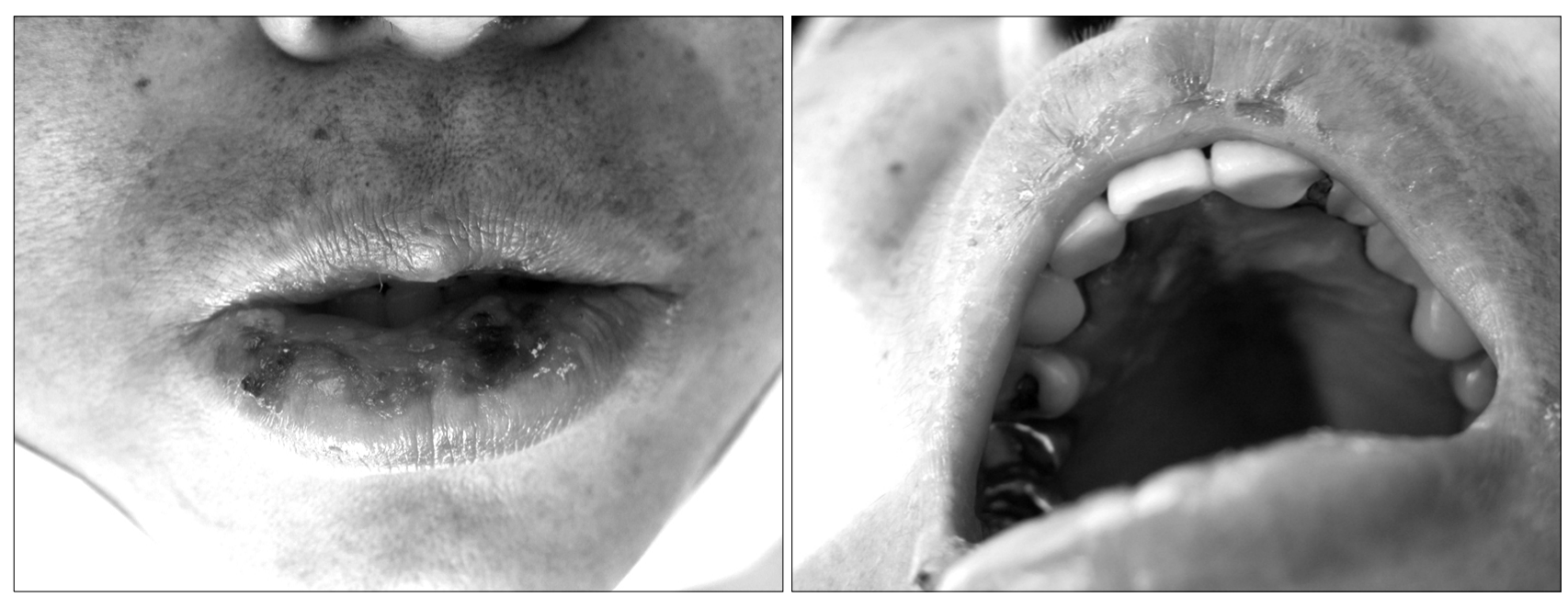

Fig. 1. Development of oral ulcerations during MMF therapy after living-donor kidney transplantation. Photographs show large painful ulcers on the lower lip and the palate.

trough level at $10 \mathrm{ng} / \mathrm{ml}$ ), MMF $1 \mathrm{~g} /$ day, and prednisolone $5 \mathrm{mg} /$ day. Methylprednisolone was administered intravenously at the dose $500 \mathrm{mg}$ before perfusion of the graft renal artery, and reduced subsequently. Basiliximab of $20 \mathrm{mg}$ was administered intravenously before reperfusion of the graftrenal artery and on postoperatioin day 4 (POD4). Urine output was sufficient postoperatively. Serum creatinine has decreased slowly to $1.4 \mathrm{mg} / \mathrm{dl}$ on day 14 . She has complained of dysphagia and has developed painful oral ulcers since POD7. On examination, there were two large ulcers up to $2.5 \mathrm{~cm}$ in size on the lower lip and palate (Fig. 1). She had mild fever without evidence of infection. Rapid aggravation of the ulcers and resultant severe pain has led to inability to eat. Fluconazole and valaciclovir were administered empirically, which was not effective. Serologies for Epstein-Barr virus, herpes simplex virus, cytomegalovirus were all negative. On POD 38, MMF was discontinued and changed to mizorbine. Pain reduced markedly following MMF discontinuation. One week later, the lesion improved and she was able to eat and drink. One month later the size of the lesions had reduced considerably.

\section{Discussion}

Meier-Kriesche et al.(6) reported that MMF significantly reduced the incidence of acute rejection in $65 \%$ and prevented renal function deterioration beyond 1 year post-transplantation (relative risk $[R R]=0.84$ ). Nowadays, MMF is widely used as maintenance immunosuppressive therapy in renal transplantation. Moreover corticosteroid-free, calcineurin inhibitor (CNI) minimization immunosuppressive regimen with weaning to MMF monotherapy achieved excellent renal function and graft survival in HLA-identical matches(7).

MMF is regarded as a well-tolerated immunosuppresant. The main adverse effects are gastrointestinal dysfunction and myelosuppression. The incidence of MMF adverse effects is associated with the dose administered. For example, the overall incidence of gastrointestinal adverse events was $52.5 \%$ and $45.5 \%$ for MMF $3 \mathrm{~g} /$ day and $2 \mathrm{~g} /$ day, respectively. Therefore most symptoms resolve with withholding or reducing MMF dosage.

Only two cases of oral ulceration accompanied by leucopenia related to MMF have been reported in the literature $(4,5)$. In both cases, patients received MMF 2 g/day. But our patient received MMF 1g/day and was not accompanied with any hematologic disorder.

Although our patient did not use sirolimus, some reported association of sirolimus and MMF with mouth ulcers $(8,9)$. Kreis et al. (10) reported the addition of sirolimus to MMF increased the occurrence of oral ulceration, because sirolimus co-administration leads to prolonged exposure to MPA. However, a positive association between MPA and oral ulceration has not yet 
been established. Conversely, Fricain et al.(11) reported that combination of sirolimus with MMF had no impact on the incidence of mouth ulcerations. Therefore further studies are required to elucidate the relationship between sirolimus, MMF and oral ulceration.

If oral ulcers are detected in renal transplant recipient, there are several possible causes(12): opportunistic infection by herpes simplex virus, cytomegalovirus or fungi, or adverse reaction of medication, especially common with sirolimus, or neutropenic ulcer.

In our case, we suspect that low dose MMF induced severe oral ulceration in the absence of other adverse effects.

The distinct, diagnostic characteristic of MMF-induced oral ulcer is rapid relief of pain after withdrawal of MMF, while regression of the lesion takes several weeks. A lesson we can learnfrom this case is that when a patient complains of oral ulcer with no other obvious cause to be found, discontinuation of MMF may be tried.

\section{REFERENCES}

1) Placebo-controlled study of mycophenolate mofetil combined with cyclosporin and corticosteroids for prevention of acute rejection. European Mycophenolate Mofetil Cooperative Study Group. Lancet 1995;345:1321-5.

2) Bullingham R, Monroe S, Nicholls A, Hale M. Pharmacokinetics and bioavailability of mycophenolate mofetil in healthy subjects after single-dose oral and intravenous administration. J Clin Pharmacol 1996;36:315-24.

3) Kahan BD. Mycophenolate mofetil. In: Morris PJ,
Knechtle SJ. Kidney transplantation. Philadelphia, PA; Saunders elsevier, 2008:277-92.

4) Garrigue V, Canet S, Dereure O, Panabieres O, Augias $D$, Chong $\mathrm{G}$, et al. Oral ulcerations in a renal transplant recipient: a mycophenolate mofetil-induced complication? Transplantation 2001;72:968-9.

5) Apostolou T, Tsagalis G, Koutroubas G, Hadjiconstantinou V, Drakopoulos S. Mycophenolate mofetil and oral ulcerations. Transplantation 2004;77:1911-2.

6) Meier-Kriesche HU, Steffen BJ, Hochberg AM, Gordon RD, Liebman MN, Morris JA, et al. Mycophenolate mofetil versus azathioprine therapy is associated with a significant protection against long-term renal allograft function deterioration. Transplantation 2003;75:1341-6.

7) Walker JK, Alloway RR, Roy-Chaudhury P, Mogilishetty G, Cardi MA, Weimert NA, et al. A prospective trial of a steroid-free/calcineurin inhibitor minimization regimen in human leukocyte antigen (HLA)-identical live donor renal transplantation. Transplantation 2009;87:408-14.

8) Dominguez J, Mahalati K, Kiberd B, McAlister VC, MacDonald AS. Conversion to rapamycin immunosuppression in renal transplant recipients: report of an initial experience. Transplantation 2000;70:1244-7.

9) MacDonald AS. A worldwide, phase III, randomized, controlled, safety and efficacy study of a sirolimus/cyclosporine regimen for prevention of acute rejection in recipients of primary mismatched renal allografts. Transplantation 2001;71:271-80.

10) Kreis H, Cisterne JM, Land W, Wramner L, Squifflet JP, Abramowicz D, et al. Sirolimus in association with mycophenolate mofetil induction for the prevention of acute graft rejection in renal allograft recipients. Transplantation 2000;69:1252-60.

11) Fricain JC, Cellerie K, Sibaud V, Catros S, Taieb A, Merville P. [Oral ulcers in kidney allograft recipients treated with sirolimus]. Ann Dermatol Venereol 2008;135:737-41.

12) Mawardi H, Pavlakis $M$, Mandelbrot $D$, Woo SB. Sirolimus oral ulcer with Cedecea davisae superinfection. Transpl Infect Dis 2010;12:446-50. 